\title{
Recently employed engineering techniques to reduce the spread of COVID-19 (corona virus disease 2019): a review study
}

\author{
Bander Saman ${ }^{1}$, Mahmoud M. A. Eid', and Marwa M. Eid ${ }^{3}$ \\ 1,2Department of Electrical Engineering, College of Engineering, Taif University, Kingdom of Saudi Arabia \\ ${ }^{3}$ Physical Therapy Department, Faculty of Applied Medical Science, Taif University, Kingdom of Saudi Arabia
}

\begin{tabular}{|c|c|}
\hline Article Info & ABSTRACT \\
\hline Article history: & \multirow{10}{*}{$\begin{array}{l}\text { The main challenges of today's global health care system are to reach to } \\
\text { strong healthcare system, to provide effective methods to eliminate the } \\
\text { increase in the number of dead and infected with virus of COVID-19. } \\
\text { Therefore, during the last few months, the great importance and efficacy of a } \\
\text { variety of engineering techniques that have greatly contributed in curbing the } \\
\text { spread of the COVID-19, and evenly help to eliminate it according to recent } \\
\text { scientific studies was highly prominent. Among these promising technologies } \\
\text { in this field we mention, but not limited to, the use of ultraviolet (UV) rays to } \\
\text { disinfection of air and surfaces. In addition, thermal imaging technology, } \\
\text { which was employed using infrared radiation for monitoring people in } \\
\text { crowded areas and human groups to determine who have abnormal } \\
\text { temperatures, so that all preventive measures are taken. Robots have also } \\
\text { been used and harnessed to perform many tasks that limit the spread of the } \\
\text { virus and maintain the integrity of the human element. Last but not least, } \\
\text { facial recognition techniques have also been used to limit the spread of this } \\
\text { pandemic. Ultraviolet radiation is one of physical therapy modalities that can } \\
\text { be used to increase the efficiency of human immune system to fight the virus. } \\
\text { In conclusion UV radiation, infrared thermal imaging, robotics, AFR } \\
\text { technologies are now widely used to reduce the spread of this virus and } \\
\text { manage the outbreak. }\end{array}$} \\
\hline Received Sep 8, 2020 & \\
\hline Revised Dec 26, 2020 & \\
\hline Accepted Jan 14, 2021 & \\
\hline Keywords: & \\
\hline COVID-19 & \\
\hline Infrared radiation & \\
\hline Robots & \\
\hline Thermal imaging & \\
\hline Ultraviolet radiation & \\
\hline
\end{tabular}

This is an open access article under the CC BY-SA license.

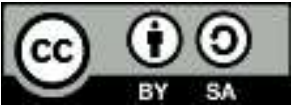

Corresponding Author:

Mahmoud M. A. Eid

Department of Electrical Engineering, College of Engineering

Taif University,

Kingdom of Saudi Arabia

Email: m.elfateh@tu.edu.sa

\section{INTRODUCTION}

Coronaviruses $(\mathrm{CoV})$ are an enormous group of positive-stranded RNA viruses known as coronaviridae, that cause sickness ranging from the common cold to more severe diseases such as severe acute respiratory syndrome (SARS-CoV) and middle east respiratory syndrome (MERS-CoV) [1, 2]. As shown from Figure 1 the structure of coronavirus has been determined by using the electron microscope, it is surrounded by spike glycoproteins that exist on their outer shell as pointed structures that look like corona or crown. Also we can see that the virus mainly consists of four proteins, S (spike), E (envelope), M (membrane), and $\mathrm{N}$ (nucleocapsid) proteins; the RNA genome exists inside the $\mathrm{N}$ protein, and the envelope of the virus consists of $\mathrm{S}, \mathrm{E}$, and $\mathrm{M}$ proteins [3-5].

At the end of December 2019, China office of the world health organization (WHO) was reported that there are a case has been associated with fever and respiratory symptoms (coughing, shortness of breath, and pneumonia) unknown etiology in Wuhan City [6]. On 11 of February 2020, the WHO announced that, 
there is a new disease, which was called COVID-19, short for coronavirus disease 2019. According to the report of the international committee on taxonomy of viruses (ICTV), this virus caused by the severe acute respiratory syndrome coronavirus-2 (SARS-CoV-2) [7]. According to the latest statistics prepared by the WHO, it was estimated the number of cumulative cases (COVID-19) around the world until 22 November 2020 reach to about 57,882,183 cases, and the number of cumulative deaths reach to about 1,377,395 deaths the details of these numbers are shown in Table 1 and Figure 2 [8].
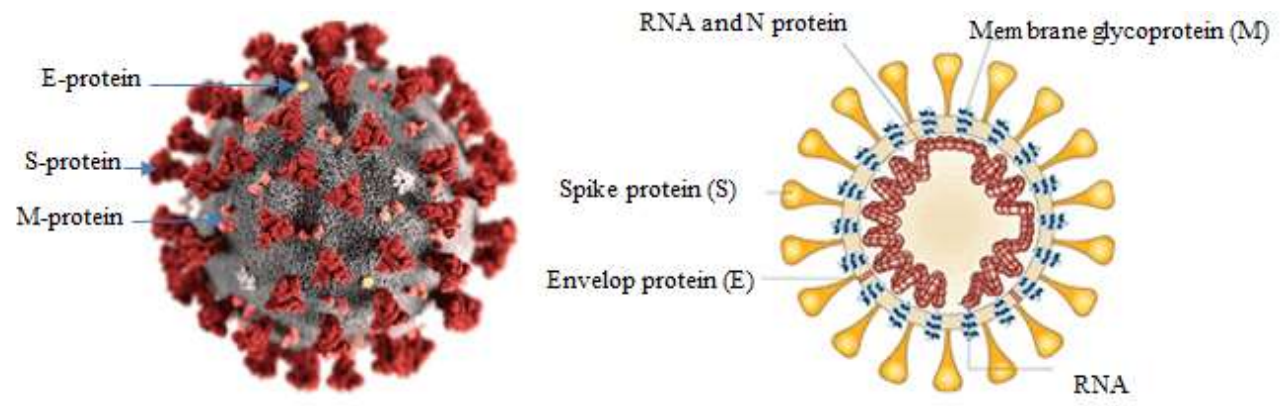

Figure 1. The structure of coronavirus

Table 1. Situation in numbers of COVID-19 cases (by WHO Region) until 22 November 2020

\begin{tabular}{lcc}
\hline & Cumulative Cases & Cumulative Deaths \\
\hline Europe & $16,873,383$ & 375,368 \\
Americas & $24,563,600$ & 697,740 \\
South-East Asia & $10,367,553$ & 158,566 \\
Eastern Mediterranean & $3,796,649$ & 96,354 \\
Africa & $1,446,041$ & 32,528 \\
Western Pacific & 834,216 & 16,816 \\
\hline
\end{tabular}

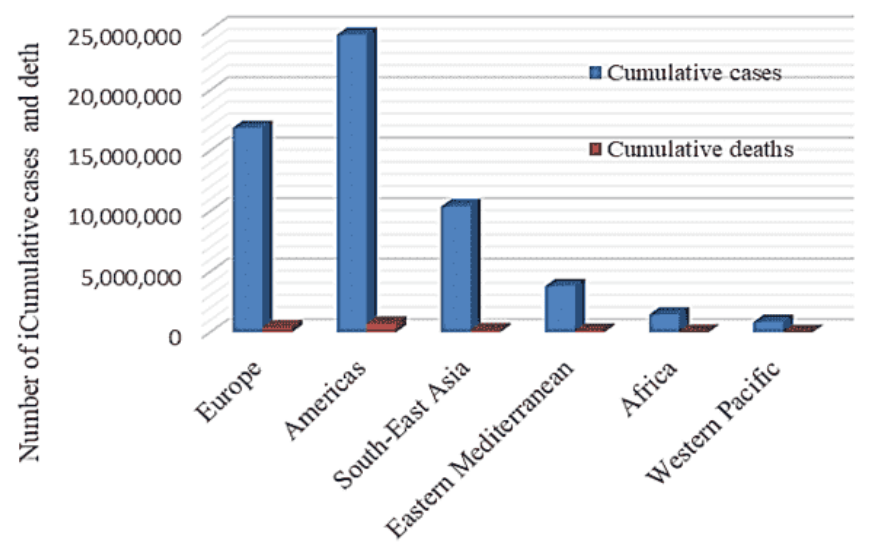

Figure 2. The number of comulative cases (COVID-19) around the world until 22 November 2020

\section{RESEARCH METHOD}

In the method section recently engineering techniques that are used to confront covid-19 will be discussed. The main challenges of today's global health care system are to reach to strong healthcare system, to provide effective methods to eliminate the increase in the number of dead and infected with virus of COVID-19. Also to develop healthy protocols to reduce the spread of this virus and reduce the number of infected people $[3,9,10]$. To achieve this target all researchers should do their best and cooperate with each other. Therefore, our ultimate goal in this research from our technical and engineering point of view is to present some engineering techniques that are used recently to confront this pandemic, in cooperation with medical sector, which will introduce some physical therapy techniques to improve the respiratory system function. 


\subsection{UV-Light radiation}

UV radiation is part of the electromagnetic radiation range of approximately 300 nanometers, from 0.1 micrometers to 0.4 micrometers. The UV spectrum can also be divided into main four subsets of bands according to their wavelength, UVA $(0.32-0.4 \mu \mathrm{m})$, UVB $(0.28-0.32 \mu \mathrm{m})$, UVC $(0.2-0.28 \mu \mathrm{m})$, and VUV (0.1-0.2 $\mu \mathrm{m})$, as shown in Figure 3 [11-13]. Regarding to UVA, it is not absorbed by the ozone layer, but it is penetrate the atmosphere, but most portion of the UVB and all UVC are absorbed by ozone layer, vapor of the water, carbon dioxide and oxygen [14].

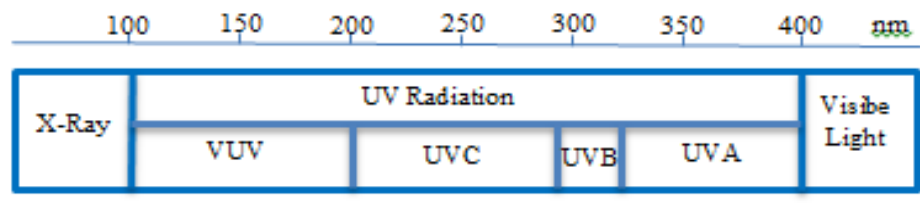

Figure 3. UV radiation spectrum

Many researchers studying the effect of UV rays, the following results were obtained:

a) UVA rays, this type is the weakest type of UV rays, which can cause progressing for the skin cells and indirectly damage the DNA of the cells.

b) UVB rays, this type is slightly stronger, which can directly cause damage to DNA, sunburn, and skin cancer.

c) UVC rays, this type is the strongest UV rays, but they do not reach Earth, because they interact with the ozone layer, but it can be generated by manufactured sources, such as mercury lamps [12].

From another point of view, the impact of regular sunlight on the human body has a great interest in medical science. Where the UV rays from the natural source provide our bodies with vitamin $\mathrm{D}$, which is very important to our health [14].

UVC light has been used extremely over a wide range from many years ago in the infection control process, which has been used for disinfecting drinking water, wastewater, air, and surfaces against a large group of pathogens and allergens for human. This process was called ultraviolet germicidal irradiation (UVGI). Where UV can damage the genetic material structure (proteins, RNA, and DNA) of viruses, bacteria, and fungi, because when these nucleic acids absorbing ultraviolet, there chemical properties will be changed. This lead to eliminate the ability of these microorganisms to increase their number. The greatest effectiveness range of UVC approximately 0.260-0.265 $\mu \mathrm{m}[11,15]$. UV radiation can also be obtained from two types of sources, either artificial, through fluorescent lamps, gas discharge lamps, light amplification by stimulated emission of radiation (LASER), or light-emitting diode (LED). This source types are used in many applications, whether in the field of medicine, industry, trade, research, or at home, the second source is natural, where sunlight is the main source of natural UV light. As of late, regular sunlight on the human body has a great interest in the science of medicine $[14,16,17]$.

There is no doubt that maintaining the cleanliness of surfaces, especially medical facilities, greatly reduces the risk of disease, transmission of infections, and control of pathogens. All of these will lead to improving human health care system and scientists can control the epidemic disease [18]. There are now major challenges to keep health facilities and public transportation such as airplanes and buses free of viruses to reduce the spread of infection. This led to an increase in the use of "touchless" disinfection techniques, including the use of UV radiation [19]. From these devices which are used now in many locations inside the hospitals, UVC light-emitting device. Also the pulsed xenon-based ultraviolet light no-touch disinfection systems (PX-UVC), which are used for medical disinfection inside many locations, such as intensive care units (ICU), operating theatres (OT), and isolation rooms, as shown in Figure 4 [18, 20, 21]. In addition, this technology is used in disinfecting the airplanes, and buses, as shown in Figures 5 and 6 [22, 23].

In China, inside the bus station, all the buses are being exposed to UVC light at night, also banks using this UVC light to disinfect their money [23]. This technique has proven effective in eliminating the spread of germs and microorganisms, but it is dangerous for workers or patients inside hospitals to be exposed to these devices, so these devices are operated in rooms after the patient has left and there are no health workers. Also, in order to protect the human element, these devices are equipped with motion sensors that shut down the device in the event that any movement inside the room is cleared $[18,20]$. Some studies have found that UV rays and heat affect the COVID-19 virus like other coronavirus (CoVs.) [3]. It is important to know that, the doses of UVC are varying in the intensity per unit area and in the exposition time duration [18]. After performing many experiments in many medical researches, it is found that, the doses of 
UV needed for a 90 to $99.999 \%$ reduction of the organisms, which are used on various inanimate surfaces depends on the type of organism, type of hard surfaces [24]. The following Table 2, summarized many results from other researches have been done on the series of Corona Viruses [25].

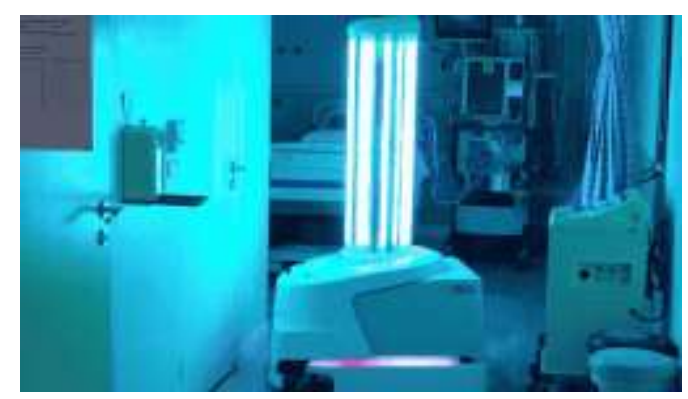

Figure 4. Ultraviolet-C disinfection robots (UVDR)

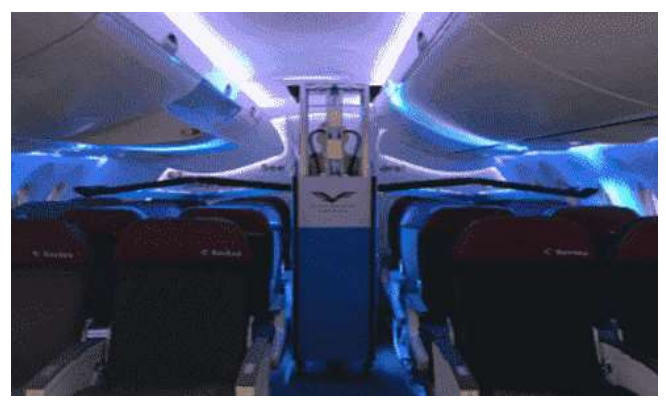

Figure 5. Dimer Ultraviolet-C disinfection in airplane

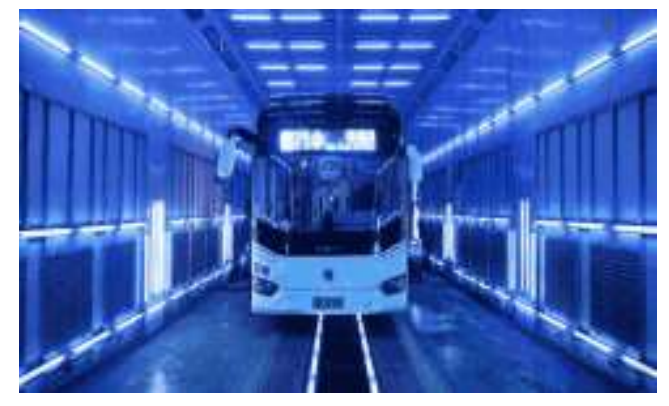

Figure 6. Ultraviolet-C disinfection in bus station

Table 2. Summary of UV light studies on Coronaviruses

\begin{tabular}{lcl}
\hline \multicolumn{1}{c}{ Microbe } & D90 dose (exposure) required & \multicolumn{1}{c}{ Source } \\
\hline Coronavirus & $7 \mathrm{~J} / \mathrm{m}^{2}$ & Walker 2007 \\
Berne virus (Coronaviridae) & $7 \mathrm{~J} / \mathrm{m}^{2}$ & Weiss 1986 \\
Murine Coronavirus (MHV) & $15 \mathrm{~J} / \mathrm{m}^{2}$ & Hirano 1978 \\
Canine Coronavirus (CCV) & $29 \mathrm{~J} / \mathrm{m}^{2}$ & Saknimit 1988 \\
Murine Coronavirus (MHV) & $29 \mathrm{~J} / \mathrm{m}^{2}$ & Saknimit 1988 \\
SARS Coronavirus CoV-P9 & $40 \mathrm{~J} / \mathrm{m}^{2}$ & Duan 2003 \\
Murine Coronavirus (MHV) & $103 \mathrm{~J} / \mathrm{m}^{2}$ & Liu 2003 \\
SARS Coronavirus (Hanoi) & $134 \mathrm{~J} / \mathrm{m}^{2}$ & Kariwa 2004 \\
SARS Coronavirus (Urbani) & $241 \mathrm{~J} / \mathrm{m}^{2}$ & Darnell 2004 \\
\hline
\end{tabular}

\subsection{Infrared thermal imaging (thermography)}

The infrared (IR) light is a part of the electromagnetic spectrum (EMS) which could not be seen with the naked human eye, in the range of $(0.78 \mu \mathrm{m}: 1000 \mu \mathrm{m})$, this means that the wavelength of IR light is longer than the visible light wavelength, and shorter than wavelengths of radio waves as showne in Figure 7 [26-28]. There are many applications for IRT in fields of surveillance, identifying human emotions from face detection, which includes facial recognition, the food industry, agriculture, medical applications, night vision, and in military application [28-30]. A thermographic camera, sometimes called thermal imager, or infrared camera, is a device which uses infrared radiation to create images similar to traditional cameras that use the visible light to produce images [31].

Thermal imaging technology has many important advantages where, this technique does not require direct contact with targets to measure its temperature, and therefore it provides us with a safety factor while using it to measure temperatures in many dangerous situations such as people who may be infectious to diseases or objects with high temperatures or dangerous materials such as acids. Likewise, this technology enables high-speed thermal scanning for both stationary and moving targets, as well as rapid temperature change patterns. In addition, it should be noted that thermal imaging is not a surgical technique nor is its 
harmful radiation such as x-rays. Also, this technology could be used in dark or light, because the object being monitored does not depend on the lighting conditions but depends on the temperature emitted from it $[28,32]$.

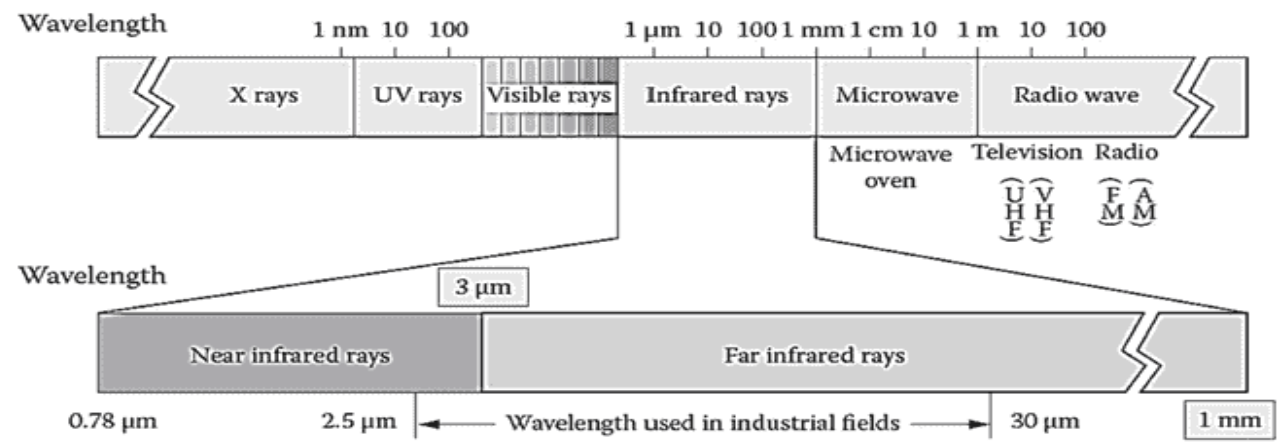

Figure 7. Spectrum of electromagnetic waves and infrared ranges

Infrared thermography (IRT) is an advanced measurement technique able to quantitatively measure surface temperatures of many objects simultaneously and faster than other devices [33-36]. One of the most symptoms which commonly appear after approximately six days when someone is infected with COVID-19 according to the reports of WHO, is the fever [3]. Therefore, the suitable procedure was to check the body temperature to easily determine the person who may be infected with COVID-19 among the crowd. However, ordinary infrared thermometer has many weaknesses, among these disadvantages; it takes a long period to take the temperature reading from everyone. In addition, the infection might be spreading to the person who is making the screening process because of the close contact with the others [1. 31, 37]. So thermal scanning of people inside the crowds or inside public buildings, companies, and medical facilities represents one of the most important means to apply precautionary measures to combating that pandemic. Moreover, to enhance the use of this technology in facing this pandemic, the drone is equipped with thermal imaging system as showne in Figure 8. Therefore, some drones being equipped with thermal cameras, some were also equipped with microphones to capture sounds, and by also using artificial intelligence (AI) solutions to process and analyze thermal images which are integrated with the sounds captured after processing them for canceling the noise, it was reached to identify other symptoms other than fever such as coughing and sneezing. This provides us with more precision to identify potential people with the virus of COVID-19 [1, 37, 38].

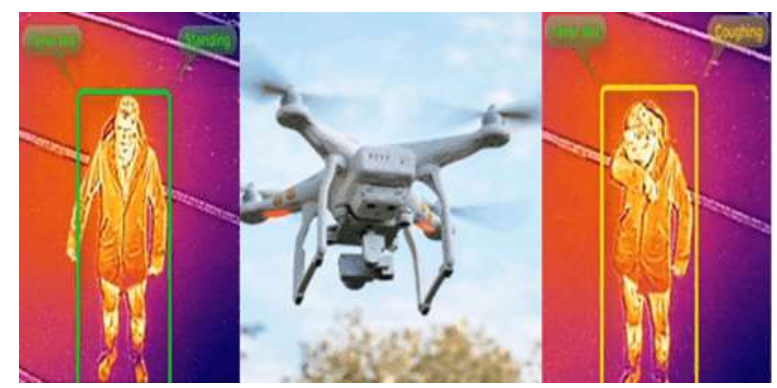

Figure 8 . Thermal screening by drone

In addition, this technology is used in surveillance system to scan suspected area using infrared camera, which is amounted on the smart helmet as shown in Figure 9, which may be equipped also with optical camera in order to enable us to identify people who are likely to be infected with the virus using facial recognition technologies. Then by employing the global positioning system (GPS), the system could locate the suspect person. By integrated with the internet of things (IOT) technology and wireless communication systems all the necessary information is sent to the pandemic management center [31]. 


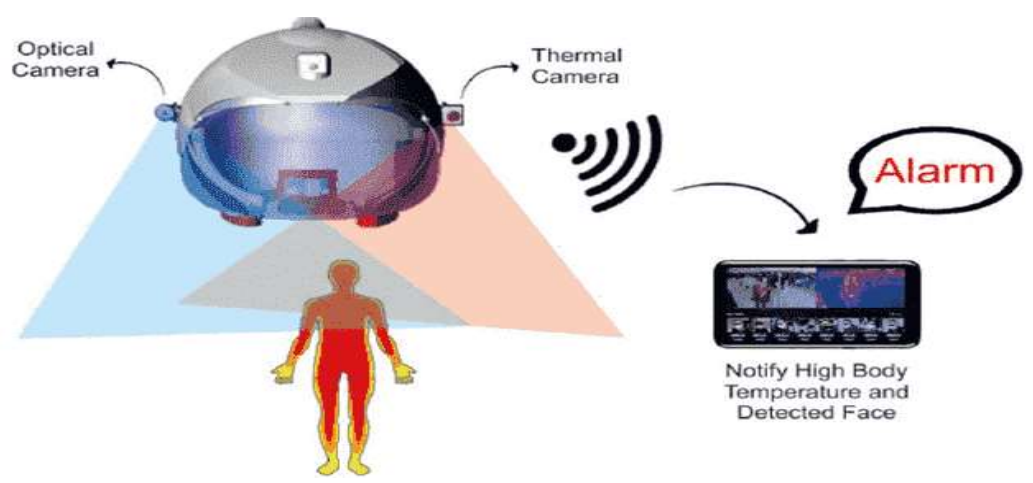

Figure 9. Smart helmet system

\subsection{Robotics}

Nowadays, there is extremely severe stress around the world on all health care systems because of a pandemic COVID-19. There is no doubt that robotic systems could participate in limiting the spread of that virus and preserving human health, especially for medical staff who are more vulnerable to infection because of their contact with patients by virtue of their work, so the main goal is to reduce the direct contact between patients and the health care workers. Therefore, there are many technical solutions to achieve this goal. Providing digital solutions in health care systems such as telehealth/telepresence, and employed robots, which perform many procedures that require direct contact with patients. Such as measuring the temperature, monitoring some clinical parameters for the patient, for example, heart rate, respiratory rate, oxygen saturation, and blood pressure, virtual screening and diagnosis, medical treatment process, delivering food, giving the patients the medical doses in its proper times, and disinfection process. Thereby, all of these procedures will decreasing the load on the workers in the medical field, especially doctors and nurses, by achieving the largest possible separation for the longest possible time between them and the patients. Figure 10 shows some types of these robots which are used in various fields $[1,39,40]$.

In addition, some robots are equipped with a thermal camera in some companies to check the temperatures of the employees before giving them the permeation to enter the facility as shown in Figure 11. If they suspect in an employee, that he has a fever they send immediately a message to his manager and does not open the door, thereby preventing him from entering the facility [41].

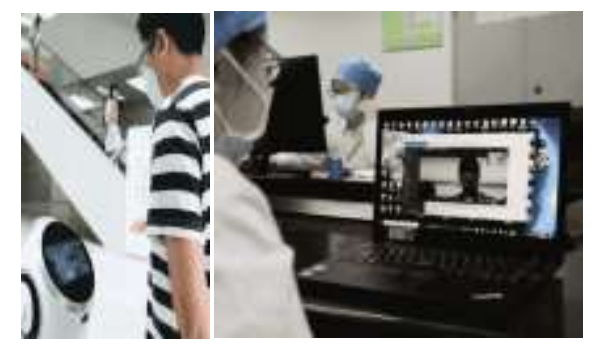

(a) Remote diagnosis robot

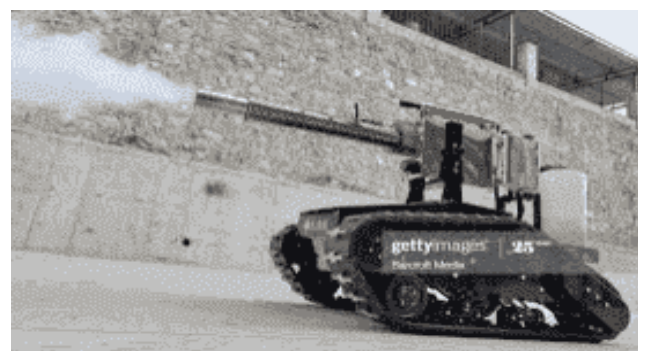

(b) Automatic disinfection robot

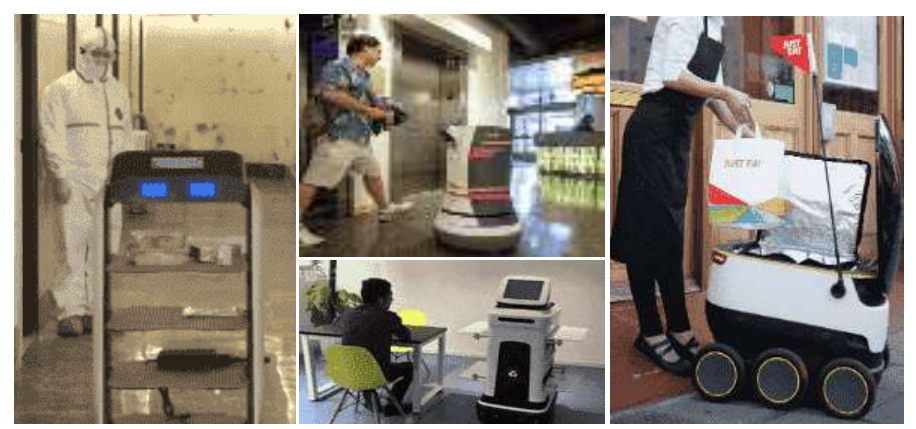

(c) Delivery services robots

Figure 10. Usage of robots in various fields 
One of the most important tools, which has an important role and many applications to confront this pandemic, is the drone. Because they could reach to difficult locations in short time and does not need direct contact with others. Drones are being used in many fields to accomplish various missions as shown in Figure 12. Such as monitoring the places of human gatherings, delivery services for both the medical and commercial sectors, purification works, broadcasting useful information to citizens, surveying the temperature of people [1,3].

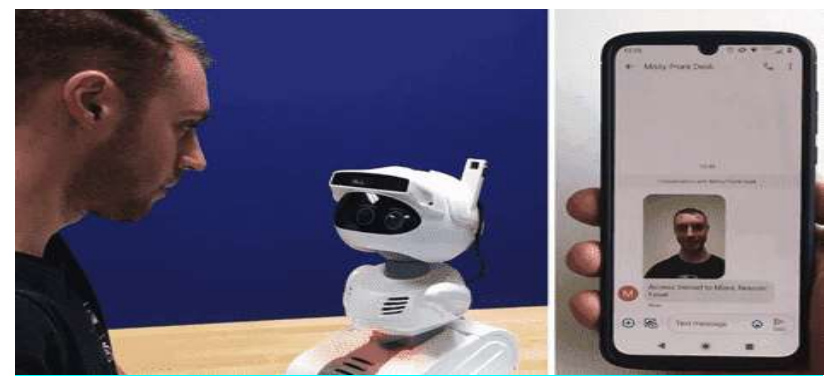

Figure 11. Robot for monitoring and checking the health of employees

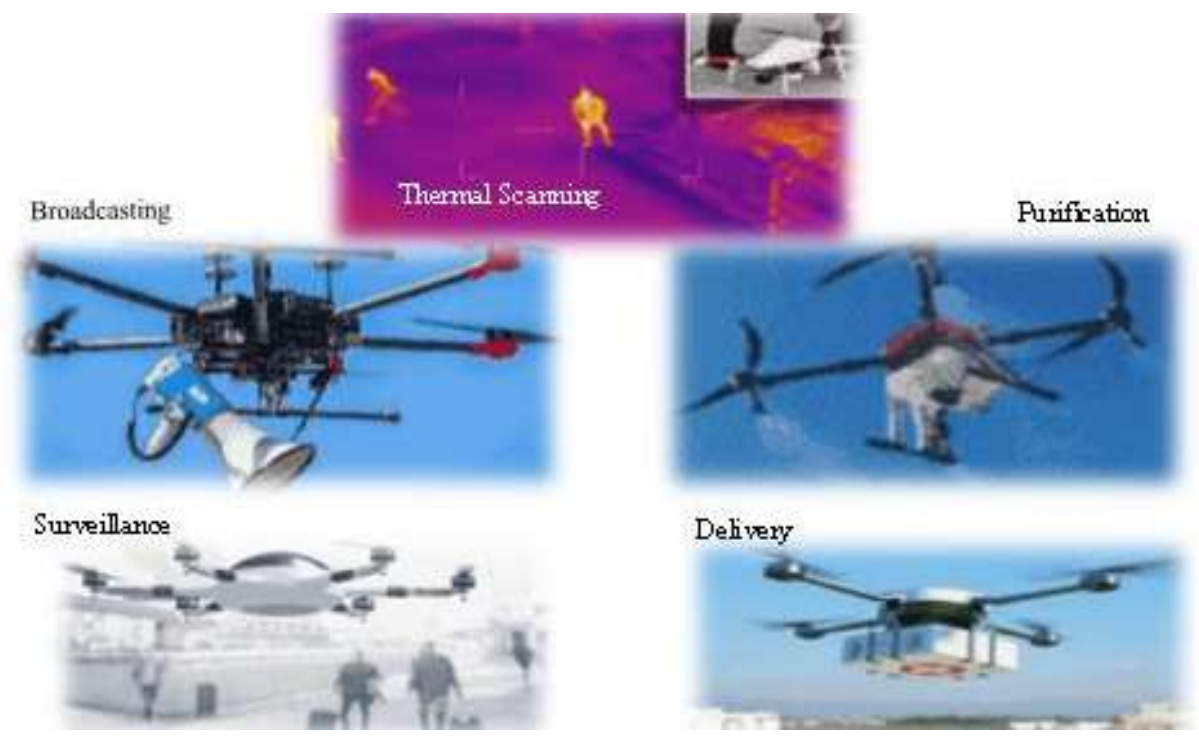

Figure 12. Drones applications in a pandemic confrontation of COVID-19

\subsection{Automated face recognition (AFR) technology}

In the beginning, it is important to mention that face recognition is a very efficient physiological biometric security system, and very safe more than other biometric security systems such as fingerprint systems, so it is widely used because there is no physical contact between the users and the device. This technology has a great advantage in these days because virus-like COVID-19 live on the surface from six hours to approximately nine days [25, 42, 43]. The techniques of AFR are the result of two integrated operations, face detection and face recognition [44, 45]. Facial recognition is being used in many applications, such as surveillance, access control, criminal identification, security, healthcare [42, 43].

The face recognition system is performed through three stages, first stage is the face detection where the image from the optical camera is scanned and this stage determines if there is any face in that image or not. The second stage is feature extraction where a group of prominent lineaments of the detected face image such as nose, mouth, eyes, and their geometrical distribution are extracted. The final stage is face recognition where the extracted features in the previous stage are compared with the stored faces in the database as shown in Figure 13. There are two main applications of face recognition, identification, and verification $[43,46]$. 


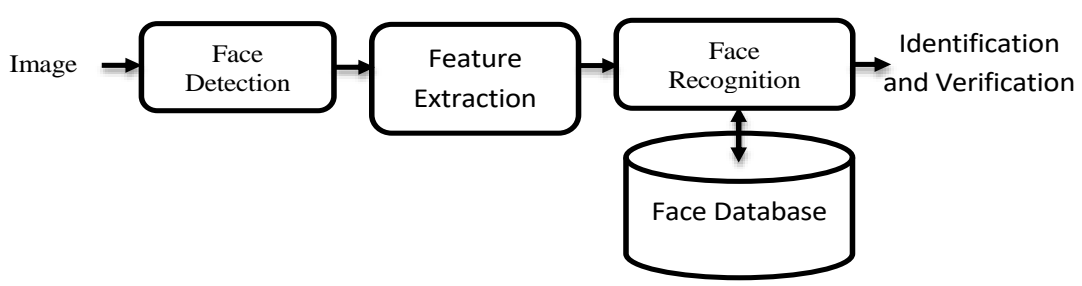

Figure 13. Block diagram of face recognition system

By using this technology, any person who may be infected with COVID-19 could be tracked. Also by integrating with other advanced technology like AI, machine recognition, machine learning, image processing, and other monitoring software programs, the system could track people who dealt with the infected person, determined their route, and reached in the shortest time, thus limiting the spread of this virus $[42,45]$. Many companies making now great efforts to develop the bio-surveillance facial recognition system, to maximize the benefit of this system by making it able to specify whether citizens are adhering to social distancing measures and wearing masks or not $[47,48]$.

\section{CONCLUSION}

In this review study, we illustrate that many healthcare, transportation, surveillance, disinfection, and delivery systems have employed different engineering techniques during this pandemic. Also, we concentrated on the UV radiation, infrared thermal imaging, robotics, AFR technologies to reduce the spread of this virus and manage the outbreak.

\section{ACKNOWLEDGEMENTS}

This work was supported by the research project grant number (1-441-71), funded by the Deanship of Scientific Research, Taif University, ministry of education, Saudia Arabia.

\section{REFERENCES}

[1] V. Chamola, V. Hassija, V. Gupta, and M. Guizani, "A Comprehensive Review of the COVID-19 Pandemic and the Role of IoT, Drones, AI, Blockchain, and 5G in Managing its Impact," IEEE Access, vol. 8, pp. 90225-90265, 2020, doi: 10.1109/ACCESS.2020.2992341.

[2] Y.-R. Guo et al., "The origin, transmission and clinical therapies on coronavirus disease 2019 (COVID-19) outbreak - an update on the status.," Mil. Med. Res., vol. 7, no. 1, p. 11, 2020, doi: 10.1186/s40779-020-00240-0.

[3] T. M. Abd El-Aziz and J. D. Stockand, "Recent progress and challenges in drug development against COVID-19 coronavirus (SARS-CoV-2) - an update on the status," Infect. Genet. Evol., vol. 83, p. 104327, Sep. 2020, doi: 10.1016/j.meegid.2020.104327.

[4] C. Sohrabi et al., "World Health Organization declares global emergency: A review of the 2019 novel coronavirus (COVID-19),” Int. J. Surg., vol. 76, pp. 71--6, 2020, doi: 10.1016/j.ijsu.2020.02.034.

[5] P. Gupta and N. Birhman, "Corona Virus Disease: A Disease Which Is Yet Not Undisease SARS-COV-2," vol. 7, pp. 668-673, Jun. 2020.

[6] M. Johnson, "Wuhan 2019 Novel Coronavirus - 2019-nCoV," Mater. Methods, vol. 10, no. 1, pp. 1-5, 2020, doi: 10.13070/mm.en.10.2867.

[7] World Health Organization, "15-Novel Coronavirus(2019-nCoV)," WHO Bull., no. February, pp. 1-7, 2020, [Online]. Available: https://www.who.int/docs/default-source/coronaviruse/situation-reports/20200211-sitrep-22ncov.pdf?sfvrsn=fb6d49b1_2.

[8] "Weekly epidemiological update - 24 November 2020." [Online]. Available: https://www.who.int/publications/m/item/weekly-epidemiological-update-24-november-2020.

[9] who, "Co V I D - 19 Strategy Up Date," Covid-19 Strateg. Updat., vol. 3, no. April, p. 18, 2020, [Online]. Available: www.who.int/emergencies/en.

[10] A. A. Al-Qahtani, "Severe Acute Respiratory Syndrome Coronavirus 2 (SARS-CoV-2): Emergence, history, basic and clinical aspects.," Saudi J. Biol. Sci., vol. 27, no. 10, pp. 2531-2538, Oct. 2020, doi: 10.1016/j.sjbs.2020.04.033.

[11] J. Wang et al., "Disinfection technology of hospital wastes and wastewater: Suggestions for disinfection strategy during coronavirus Disease 2019 (COVID-19) pandemic in China," Environ. Pollut., vol. 262, p. 114665, 2020, doi: 10.1016/j.envpol.2020.114665.

[12] S. Safari, S. Eshraghi Dehkordy, M. Kazemi, H. Dehghan, and B. Mahaki, "Ultraviolet Radiation Emissions and Illuminance in Different Brands of Compact Fluorescent Lamps,” Int. J. Photoenergy, vol. 2015, p. 504674, 2015, 
doi: $10.1155 / 2015 / 504674$.

[13] X. Zhang, K. Dong, Y. Wang, D. Xu, and J. Jiang, "Research on the Parameter Optimization of Electronic Ballast for UV-Lamps Considering Its Lifetime and UVC Irradiance," IEEE Access, vol. 6, pp. 11931-11939, 2018, doi: 10.1109/ACCESS.2018.2802481.

[14] S.-T. Oh and J.-H. Lim, "Development and Effect Analysis of UVB-LED General Lighting to Support Vitamin D Synthesis," Appl. Sci., vol. 10, no. 3, p. 889, 2020, doi: 10.3390/app10030889.

[15] D. Mills, D. A. Harnish, C. Lawrence, M. Sandoval-Powers, and B. K. Heimbuch, "Ultraviolet germicidal irradiation of influenza-contaminated N95 filtering facepiece respirators," Am. J. Infect. Control, vol. 46, no. 7, pp. e49-e55, 2018, doi: 10.1016/j.ajic.2018.02.018.

[16] "Radiation: Ultraviolet (UV) radiation." [Online]. Available: https://www.who.int/news-room/q-a-detail/radiationultraviolet-(uv).

[17] A. Tamuri, A. Muhamad, S. Akmal, M. Lani, M. Kundwal, and Y. Daud, Ultravoilet (UV) Light Spectrum of flourescent lamps. 2014.

[18] B. Casini et al., "Evaluation of an Ultraviolet C (UVC) Light-Emitting Device for Disinfection of High Touch Surfaces in Hospital Critical Areas.," Int. J. Environ. Res. Public Health, vol. 16, no. 19, Sep. 2019, doi: 10.3390/ijerph16193572.

[19] J. M. Boyce and C. J. Donskey, "Understanding ultraviolet light surface decontamination in hospital rooms: A primer," Infect. Control Hosp. Epidemiol., vol. 40, no. 9, pp. 1030-1035, 2019, doi: 10.1017/ice.2019.161.

[20] A. Elgujja, S. Ezreqat, and H. Altalhi, "Review of the Efficacy of Ultraviolet C for Surface Decontamination," $J$. Nat. Sci. Med., vol. 3, pp. 8-12, Jan. 2020, doi: 10.4103/JNSM.JNSM_21_19.

[21] "Coronavirus Pandemic: A Call to Action for the Robotics Community - IEEE Spectrum." [Online]. Available: https://spectrum.ieee.org/automaton/robotics/medical-robots/coronavirus-pandemic-call-to-action-roboticscommunity.

[22] "Flight of the GermFalcon: How a Potential Coronavirus-Killing Airplane Sterilizer Was Born - IEEE Spectrum." [Online]. Available: https://spectrum.ieee.org/tech-talk/aerospace/aviation/germfalcon-coronavirus-airplaneultraviolet-sterilizer-news.

[23] "Can you kill coronavirus with UV light? - BBC Future." [Online]. Available: https://www.bbc.com/future/article/20200327-can-you-kill-coronavirus-with-uv-light.

[24] L. Sifuentes, "Determination of Ultraviolet Light Doses Needed to Inactivate Bacteria and Viruses on Hard," Am. J. Infect. Control, vol. 43, Jun. 2015, doi: 10.1016/j.ajic.2015.04.060.

[25] W. Kowalski, T. Walsh, and V. Petraitis, 2020 COVID-19 Coronavirus Ultraviolet Susceptibility. 2020.

[26] S. Aboud, A. Altemimi, A. Al-Hilphy, Y.-C. Lee, and F. Cacciola, "molecules A Comprehensive Review on Infrared Heating Applications in Food Processing," Molecules, vol. 24, pp. 2-21, 2019, doi: $10.3390 /$ molecules 24224125 .

[27] K. Shokrollahi, E. Raymond, and M. S. C. Murison, "Lasers: Principles and Surgical Applications," J. Surg., vol. 2, no. 1, pp. 28-34, 2004, doi: 10.1016/S1743-9191(06)60023-X

[28] M. Rai, "Thermal imaging system and its real time applications: a survey,” J. Eng. Technol., vol. 62, Jun. 2018.

[29] S. Shaikh, N. Akhter, and R. Manza, "Current Trends in the Application of Thermal Imaging in Medical Condition Analysis,” vol. 8, pp. 2708-2712, Jun. 2019.

[30] C. Lavers, K. Franks, M. Floyd, and A. Plowman, "Application of remote thermal imaging and night vision technology to improve endangered wildlife resource management with minimal animal distress and hazard to humans," J. Phys. Conf. Ser., vol. 15, p. 207, Aug. 2005, doi: 10.1088/1742-6596/15/1/035.

[31] A. P. D. M. Abdulrazaq, H. Zuhriyah, S. Al-Zubaidi, S. Karim, R. Ramli, and E. Yusuf, "Novel COVID-19 DEtection And Diagnosis System Using IoT Based smart helmet," Int. J. Psychosoc. Rehabil., vol. 24, pp. 22962303, Mar. 2020, doi: 10.37200/IJPR/V24I7/PR270221.

[32] R. Usamentiaga, P. Venegas, J. Guerediaga, L. Vega, J. Molleda, and F. G. Bulnes, "Infrared thermography for temperature measurement and non-destructive testing," Sensors (Basel)., vol. 14, no. 7, pp. 12305-12348, Jul. 2014, doi: $10.3390 / \mathrm{s} 140712305$.

[33] G. Planinsic, "Infrared Thermal Imaging: Fundamentals, Research and Applications," Eur. J. Phys., vol. 32, no. 5, p. 1431,2011 , doi: $10.1088 / 0143-0807 / 32 / 5 / b 01$.

[34] S. R. Johnson, S. Rao, S. B. Hussey, P. S. Morley, and J. L. Traub-Dargatz, "Thermographic Eye Temperature as an Index to Body Temperature in Ponies," J. Equine Vet. Sci., vol. 31, no. 2, pp. 63-66, 2011, doi: 10.1016/j.jevs.2010.12.004.

[35] M. Ö. Korukçu and M. Kilic, "The usage of IR thermography for the temperature measurements inside an automobile cabin," Int. Commun. Heat Mass Transf., vol. 36, no. 8, pp. 872-877, 2009, doi: 10.1016/j.icheatmasstransfer.2009.04.010.

[36] O. Hennessy and S. M. Potter, "Use of infrared thermography for the assessment of free flap perforators in autologous breast reconstruction: A systematic review," JPRAS Open, vol. 23, pp. 60-70, 2020, doi: 10.1016/j.jpra.2019.11.006.

[37] A. P. D. M. Abdulrazaq, N. Hazairin, S. Al-Zubaidi, S. Karim, S. Mustapha, and E. Yusuf, "toward a novel design for coronavirus detection and diagnosis system using iot based drone technology," Int. J. Psychosoc. Rehabil., vol. 24, pp. 2287-2295, Mar. 2020, doi: 10.37200/IJPR/V24I7/PR270220.

[38] "Drones and the Coronavirus: Do These Applications Make Sense? (Updated) - WeRobotics Blog." [Online]. Available: https://blog.werobotics.org/2020/04/09/drones-coronavirus-no-sense/.

[39] M. Tavakoli, J. Carriere, and A. Torabi, Robotics For COVID-19: How Can Robots Help Health Care in the Fight Against Coronavirus. 2020. 
[40] G.-Z. Yang et al., "Combating COVID-19-The role of robotics in managing public health and infectious diseases," Sci. Robot., vol. 5, no. 40, p. eabb5589, Mar. 2020, doi: 10.1126/scirobotics.abb5589.

[41] "Misty II: A Partner in COVID-19 Safety and Wellness." [Online]. Available: https://www.mistyrobotics.com/usecases/robot-for-covid-19-coronavirus-safety-wellness/.

[42] I. Taleb, M. E. A. Ouis, and M. O. Mammar, "Access control using automated face recognition: Based on the PCA \& LDA algorithms," in 2014 4th International Symposium ISKO-Maghreb: Concepts and Tools for knowledge Management (ISKO-Maghreb), 2014, pp. 1-5, doi: 10.1109/ISKO-Maghreb.2014.7033455.

[43] M. Hassaballah and S. Aly, "Face Recognition: Challenges, Achievements, and Future Directions," IET Comput. Vis., vol. 9, pp. 614-626, Aug. 2015, doi: 10.1049/iet-cvi.2014.0084.

[44] J. Olszewska, "Automated Face Recognition: Challenges and Solutions," 2016.

[45] J. Yu, Y. Zhao, S. Zhu, A. Wang, and Y. Wang, "A Bibliometric Analysis on Face Recognition Technology Research," in 2018 IEEE International Conference of Safety Produce Informatization (IICSPI), 2018, pp. 755-759, doi: 10.1109/IICSPI.2018.8690483.

[46] Y. Kortli, M. Jridi, A. Al Falou, and M. Atri, "Face Recognition Systems: A Survey," Sensors (Basel)., vol. 20 , no. 2, p. 342, Jan. 2020, doi: 10.3390/s20020342.

[47] "Straight Talk about Face Masks and Face Recognition | 2020-04-14 | Security Magazine.” [Online]. Available: https://www.securitymagazine.com/articles/92140-straight-talk-about-face-masks-and-face-recognition.

[48] "Covid-19 products," Biometric Technol. Today, vol. 2020, no. 4, p. 4, Apr. 2020, doi: 10.1016/S09694765(20)30048-5.

\section{BIOGRAPHIES OF AUTHORS}

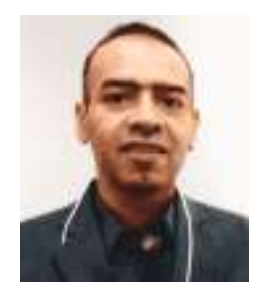

Dr. Bander Saman received his doctorate from the University of Connecticut, USA. He is currently an Assistant Professor in the Electrical Engin

eering Department, Faculty of Engineering at Taif University (KSA). His research interests are simulation of quantum dot/well FETs, bioMEMS, biomedical instrumentation, and Occupational Safety and Health OSH.

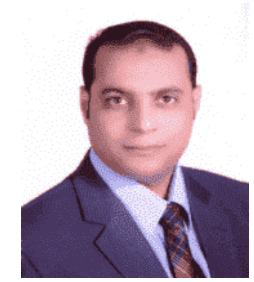

Dr. Mohamoud M. A. Eid was born in gharbiya State, Egypt, in 1977. Received a B.Sc., M.Sc., $\mathrm{Ph} . \mathrm{D}$. degrees in the Electronics Communication Engineering Department from Faculty of Electronic Engineering, Menoufia University in 2002, 2007, and 2012 respectively. Currently, He joins now the Taif University as an Assistant Professor in the Electrical Engineering Department, Faculty of Engineering at Taif University (KSA). His scientific master science thesis has focused on optical amplifiers in optical access communication systems. His interesting research mainly focuses on optical sources, amplifiers, detectors, sensors, and optoelectronic devices.

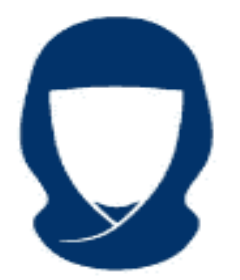

Ass. Prof. Dr. Marwa M. Eid B.Sc., M.Sc., Ph.D. degrees in physical therapy, Cairo University. Currently, she joins now Taif University as an Associate Professor in the Physical Therapy Department, Faculty of Applied Medical Science at Taif University (KSA). Her research interest is to search about innovative physical therapy techniques in different health sectors. 